\title{
Analysis of Social Media for Marketing CPA Services in Australia
}

\author{
John A. De Leon \\ Texas A\&M University-Corpus Christi \\ Katherine Taken Smith \\ Texas A\&M University-Corpus Christi \\ Lawrence Murphy Smith \\ Texas A\&M University-Corpus Christi
}

Public accounting firms increasingly use social media to market their services. Determining which social media platforms are the best fit for the firm and its clients can be a challenge. This study examines the use of social media by major Certified Public Accounting firms in Australia, according to the following measures: revenue, number of partners, number of offices, and gender distribution among partners. Findings indicate that social media can play an important role in marketing CPA services. Social media use differs according to revenue and total partners, but not number of offices. In addition, the findings show a gender difference exists, that social media use varies by the firm's gender make-up, as measured by the female proportion of the firm's partnership.

Keywords: marketing for accountants, social media, CPA firms, social media marketing

\section{INTRODUCTION}

Past research shows that public accounting firms use social media to provide information and interact with clients. However, the public accounting firms examined in those studies have been US firms only (Chamberlain, Rudolph, \& Smith, 2019b; Eschenbrenner, Nah \& Telaprolu, 2015; Smith, \& Smith, 2018). This paper specifically focuses on Australian public accounting firms. Australia's A $\$ 2$ trillion economy is booming as consumers and businesses are bouncing back from the pandemic. Consumers are ready to spend and businesses are ready to engage new customers (Swati, 2021). Many businesses, including public accounting firms, use social media platforms as a means to interact with current and prospective clients. Research shows that social media has become more than a mere communication device or information source. Social media is now a source of influence (Hanna, Rohma, \& Crittendenb, 2011; Mangold \& Smith, 2011).

The purpose of this study is to analyze social media use by Australian Certified Public Accountant (CPA) firms according to revenue, number of partners, number of offices, and gender distribution among partners. We use the technology-organization-environment (TOE) framework (DePietro, Wiarda, \& Fleischer, 1990) as a basis for our investigation. These findings will assist Australian CPA firms in 
strategically planning their investment into social media initiatives. This paper will also be of interest to academic researchers who focus on accounting practice and the impact of innovative technologies.

\section{THEORY AND LITERATURE REVIEW}

Social media has had a revolutionary impact on the way people gather and distribute information both in personal spheres and in the business environment. Social media platforms facilitate this information sharing, making it simple to obtain information as well as post information. Several theoretical models have been used to explain the widespread adoption and popularity of social media. For example, Shirky (2010) posits that intrinsic rewards of posting information to a social media site are key to its popularity and use, and that cognitive surplus theory can explain how technology turns consumers into collaborators. Alternatively, the technology-organization-environment (TOE) framework (DePietro et al., 1990) suggests that factors related to technoological, organizational, and enviromental context can explain the adoption of social media.

Before social media platforms existed, social network theory enabled researchers to examine the interplay of social relationships in sending and receiving information, guiding media or personal impacts, and facilitating change in behavior or attitudes (Liu, Sidhu, Beacom, \& Valente, 2017). Carr \& Hayes (2015) contend that models and theories regarding social media should be driven by the communicative element, not the specific medium. Doing so will help ensure that the model stays meaningful over time, even as media technologies change. According to adaptive structuration theory, people can adopt social media technology and use it for either its designed purpose or an unintended purpose (Desanctis \& Poole, 1994). Another theory with ramifications to social media use is privacy management theory, which concerns how people communicate or withhold messages based on transmission platform and possible recipients (Petronio, 1991).

Presented below are relevant past research studies that highlight opportunities and challenges provided to firms as they begin to implement social media activities. This is followed by a brief review of the disparate use of social media by firms. Last, the technology-organization-environment framework is described to highlight a need to study social media use by firms within specific contexts.

\section{DEFINITION OF SOCIAL MEDIA}

Social media platforms are among the most popular sites on the Internet. The initial phase of the Internet, Web 1.0, was dominated by a "read-only" structure. Web pages were static and intended mainly as repositories of information (Rudman, 2007). Users would interact with web pages in essentially the same way as they would interact with a printed encyclopedia or directory; with a topic of interest in mind, users could search and find information and explore related linked pages.

The early 2000s saw a rapid transition into the era of Web 2.0, an era marked by a shift from users as passive viewers of online content, "read-only" use, into users as contributors and co-creators, "read-write" use (S. M. Baird, Marsh, Lawrentschuk, Smart, \& Chow, 2019; Rudman, 2007). Web 2.0 is a set of interrelated technologies that enabled web pages to become dynamic and interconnected (O'Reilly, 2007). Under these technologies, users became able to both find information and contribute to a growing body of knowledge.

Web 2.0 created the technological and ideological shifts that enabled social media platforms to become ubiquitous (Kaplan \& Haenlein, 2010). Berthon, Pitt, Plangger, \& Shappiro (2012) argue that Web 2.0 resulted in three major shifts, a shift from desktop computing to web-driven interfaces, a shift from value created by firms to value created by consumers, and a shift of power away from the firm to the consumer. These shifts and related changes brought about by Web 2.0 enabled social media platforms to exist and set the stage for their popularity (Kaplan \& Haenlein, 2010; Olanrewaju et al., 2020).

The term social media became broadly popular in 2005 as a label for various sites that enabled users to create content and share it broadly (Kaplan \& Haenlein, 2010). One example, Facebook, founded in 2004, allows users to post their own or other's content and allows for conversations surrounding existing content. 
By 2018 Facebook had grown to over 1.45 billion active users (S. M. Baird et al., 2019), with over 50 million business in various industries and countries represented on the platform (Olanrewaju, Hossain, Whiteside, \& Mercieca, 2020).

The popularity of social media as a whole has led to the emergence of literally hundreds of social media platforms that have been developed for a wide variety of purposes (Forbes, Goodman, \& Dolan, 2015). Simply stated, social media is both the platform and content created and shared through the interactions of individuals and organizations (Berthon et al., 2012; Kietzmann, Hermkens, McCarthy, \& Silvestre, 2011). A more comprehensive definition offered by Kapoor et al. (2018) defines social media as the "various userdriven platforms that facilitate diffusion of compelling content, dialog creation, and communication to a broader audience. It is essentially a digital space created by the people and for the people and provides an environment that is conducive for interactions and networking to occur at different levels" (p. 536). Social media's distinguishing features require content that is user created or co-created, widely distributed, and highly accessible (Berthon et al., 2012; Forbes et al., 2015; Karahanna, Xu, Xu, \& Zhang, 2018).

\section{OPPORTUNITIES AND CHALLENGES OF SOCIAL MEDIA}

In 2017 approximately 40 percent of the world's population was estimated to be active on social media sites (Williams, 2017). While individuals often participate in social media platforms to connect with other individuals, it is estimated that over half of all Instagram users have chosen to receive updates about businesses important to them and similar percentages have been observed on most dominant social media platforms (Olanrewaju et al., 2020). This broad adoption by the general public and willingness to engage with firms as peers provides many opportunities and challenges for firms (Berthon et al., 2012).

While there are many opportunities for organizations to use social media platforms, most are centered around three key areas. First, social media platforms serve as a source of information for both consumers and the firm (Zeng, Chen, Lusch, \& Li, 2010). As a source of information, social media platforms allow firms to disseminate and receive information. This information can be about general topics likely to interest the firms set of potential and existing customers, or it may be information specifically about the firm (Mangold \& Smith, 2011).

By disseminating general information, firms are also able to create value and foster brand engagement (Seraj, 2012). By disseminating firm-specific information, the firm creates value through increased transparency, approachability, and engagement with both internal and external constituents (Weinberg \& Pehlivan, 2011). For instance, many firms use social media as an avenue for corporate reporting (Uyar \& Boyar, 2015); Yang and Liu (2017) found firms were able to influence outcomes by highlighting positive information while deemphasizing negative information. By developing these relationships firms are better able to conduct market research (Forbes et al., 2015; Mangold \& Smith, 2011), increase brand engagement (C. H. Baird \& Parasnis, 2011), and create communities that foster brand loyalty (Culnan, McHugh, \& Zubillaga, 2010; Laverie, Humphrey, Velikova, Dodd, \& Wilcox, 2011). These deeper relationships may lead to increased communication and co-creation of knowledge (Huang, Baptista, \& Galliers, 2013).

Second, social media platforms serve as a marketing tool for the firm (Zeng et al., 2010). Many firms have integrated social media into their traditional marketing mix for a wide variety of purposes. For instance, firms have used social media platforms to create behavioral contagion to their benefit during product launches by leveraging word-of-mouth and peer influence effects (Aral \& Walker, 2011). Forbes et al. (2015) reported that over half of US-based wineries utilized Facebook to generate customer sales. Other firms have used social media as a way to enhance their corporate image by dissemination selected information about their activities, such as corporate social responsibility initiatives (e.g. Linnhoff, Volovich, Martin, \& Smith, 2017; Martin, Smith, \& Smith, 2017).

By skillfully selecting and distributing positive or otherwise flattering information, a firm can build reputational capital; in addition, these positive posts are also more likely to be shared in online communities (Monesson, 2014). Some firms have used social media as a means to increase brand awareness. Stelzner (2011) found that social media activity increased search engine rankings for almost two-thirds of firms in 
their sample. Ultimately greater brand awareness is likely to lead to greater revenues (Momany \& Alshboul, 2016).

Third, social media platforms serve as a means for managing stakeholder relationships (Zeng et al., 2010). As previously noted, social media platforms enable a rapid exchange of information to and from all participants. Firms are able to use social media to build goodwill and improve their reputation. One way firms do this is by highlighting their socially responsible initiatives (e.g. Linnhoff et al., 2017; Martin et al., 2017). Another way firms build goodwill and improve their reputation is by responding to customer complaints and issues posted in online communities (Hoffman \& Fodor, 2010). Firms may also use social media to manage internal stakeholders, for instance, larger accounting firms often use social media to help socialize new hires into the firm's unique culture and operating procedures (Eschenbrenner et al, 2015).

Despite the many opportunities provided by social media use for firms, there are also many challenges faced by firms when implementing social media into their key activities. Two major challenges involve justifying the use of social media through traditional measures such as return on investment and managing the associated financial, legal, and reputational liabilities. First, there does not currently exist a standard measure to capture the value of social media for firms (Hoffman \& Fodor, 2010). While on the whole researchers have correlated social media activity to increased financial performance (Alarcón-del-Amo, Rialp-Criado, \& Rialp-Criado, 2018; Franco, Haase, \& Pereira, 2016; Tajvidi \& Karami, 2017), the lack of standard measures combined with the difficulty in measuring value have led some to question if social media is a value-creating activity (Dooley, Jones, \& Iverson, 2014) and has led some senior managers to view social media as a waste of resources (Berthon et al., 2012; Hoffman \& Fodor, 2010). While a uniformly accepted measure does not exist, Hoffman \& Fodor (2010) offer several proxy measures in an attempt to justify social media activities.

Second, and more difficult to address are the associated liabilities. Concerning financial liabilities, social media use requires the firm to dedicate financial resources to manage its profile (Barnes, 2010). The firm must either redirect one or more employees from other value-creating activities to social media platforms, hire additional employees to manage their profiles, or hire a third party. While some firms may attempt to only marginally engage in social media activities to minimize its financial burden, successful outcomes generally require the firm to demonstrate considerable activity (Kaplan \& Haenlein, 2010). Adding to these costs is the need to identify the specific platforms where potential and existing customers are active, and the need to create or otherwise curate content that is likely to engage the firms intended audiences and that reinforce or create the appropriate marketing messages (Smith, 2017).

Aside from the financial liabilities, social media activities also create legal liabilities. For instance, dissatisfied employees within the firm may use social media to create negative messages directed to the firm, or other stakeholders (Barnes, 2010), while improperly trained employees may create content that exposes the firm to litigation (e.g. Moses, McNeese, Feld, \& Feld, 2014).

Finally, firms engaged in social media are also exposed to reputational liabilities. Berthon et al. (2012) note that local events seldom remain local and general events seldom remain general, that is to say, the firm's actions are likely to be broadcast to a broad audience, and general events are likely to be applied to local firms. For instance, in one well-known case involving United Airlines, a guitar was broken while being transported during a flight. The guitar owner, Dave Carroll, also a musician, was dissatisfied with the handling of the situation by United Airlines and created a video titled "United Breaks Guitars." The video captured the attention of audiences around the world and was credited with a substantial drop in market value for United Airlines; estimates range up to 180 million dollars (Sawhney, 2009). In addition, the video caused a reduction in reputational value and a decrease in revenue from a drop in bookings (Dwivedi et al., 2018; Etter, Ravasi, \& Colleoni, 2019).

\section{USE OF SOCIAL MEDIA BY FIRMS}

Despite the challenges associated with social media, the many opportunities have led to an almost universal adoption by firms of all sizes. Yet, as expected from a TOE framework, while the use of social media may be ubiquitous, prior research has demonstrated substantial differences in use at the country, 
industry, and firm levels of analysis. For instance, in a study of wineries, Forbes et al. (2015) found that Australian wineries were significantly less likely to engage in social media compared to American wineries, more likely to engage in social media compared to French and German wineries, and demonstrated equal participation as New Zealander wineries. Similarly, in a study of otolaryngologists, Baird et al. (2019) found significant differences in the utilization of social media by area specialization, for instance, otolaryngologists specializing in medicolegal issues had fewer accounts than those specializing in facial plastics. Further, Eschenbrenner, Nah, and Telaprolu (2015) found differences in how social media was used based on the size and reputation of accounting firms.

The technology-organization-environment (TOE) framework created by DePietro, Wiarda, and Fleischer (1990) provides some insight into why these differences may exist. For instance, the framework would suggest technological factors like available bandwidth are likely to have an impact; thus, countries with higher average bandwidth are more likely to use media-heavy platforms such as YouTube compared to countries with low bandwidth (Berthon et al., 2012). The framework would suggest that organizational factors such as firm age and size may influence the adoption and use of social media.

In Australia, research has demonstrated a differential rate of adoption and use between small, medium, and large-sized firms (Olanrewaju et al., 2020). Other research has demonstrated that organizational culture and leadership are important organizational factors in regards to social media adoption and use (Brink, 2017; Guinan, Parise, \& Rollag, 2014; Toombs \& Harlow, 2014). Finally, the framework would suggest that environmental factors such as a country's culture and government may have measurable impacts on adoption and use. For instance, the use of social media platforms in China is often restricted and censored, leading users to different platforms and shaping content (Yuan, 2018).

Given the various benefits and challenges firms face when implementing social media activities into their firms and the contextual factors that help shape a firms decision, we chose to investigate whether social media use by major Australian CPA firms varies according several organizational factors, specifically, firm size characteristics such as total revenue, total partners, and total offices, and top management characteristic, specifically gender make-up, as measured by the percentage of female partners.

\section{RESEARCH QUESTIONS, SAMPLE, AND METHODOLOGY}

As the use of social media increases, business firms and CPA firms strive to assess the social media platforms that are the ideal fit for their firms and clients. In selecting a social media platform, it may be helpful to know what the leading CPA firms are using in order to positively impact organizational reputation (Etter, Ravasi, \& Colleoni, 2019); thus, the first research question is as follows.

\section{RQ1 Which social media platforms are being used by major Australian CPA firms?}

Given that different social media platforms have their own special features and are used by people based on unique needs, the question is whether specific social media platforms are more beneficial for firms, depending on total revenues, number of partners, number of offices, or gender make-up of partners. Prior research using the TOE's framework has found that adoption decisions concerning automatic warehousing systems and supply chain management systems have been impacted by both firm size and top management characteristics (cf. Hao, Shi, Shi, \& Yang, 2020; Lin, 2014). Thereby, the second research question concerns an examination of the social media platform use according to organizational factors. In deciding which social media platforms to use, it is helpful for a manager to know what other CPA firms of similar standing are using.

$\boldsymbol{R Q 2}$ Does social media use vary according to total revenue, total partners, total offices, and the percentage of female partners?

The methodology employed in the present study was developed in prior research regarding social media usage (cf., Chamberlain, Rudolph, Smith, \& Smith, 2019a; Chamberlain et al., 2019b; Smith, 2017). The 
analysis, using t-tests, will determine whether significant differences exist between high-social-media-use firms and low-social-media-use firms according to total revenue, total partners, total offices, and the percentage of female partners.

The sample firms were selected from the top 100 CPA firms listed in the Australian Financial Review (AFR, 2018). Each year, the Review provides information on these firms, including revenues, total partners, total offices, and the percentage of female partners. The final sample included 97 firms, as social media data was unavailable for three of the listed firms (one due to merger and two due to website unavailability at the time of data collection).

The final sample of 97 compares favorably to sample sizes used in prior financial-related studies, such as concerning energy companies social media, sample size 28 (Chamberlain et al., 2019a); US CPA firms social media, sample size 100 (Chamberlain et al., 2019b); hospitals social media, sample size 100 (Smith, 2017); GMO products firms, sample size 30 (Martin, Durr, Smith, Finke, \& Cherry, 2017); and food products firms, sample size 30 (Martin, Smith, \& Smith, 2016).

\section{RESULTS}

The website of each CPA firm was examined to tabulate the social media platforms employed at the firm. Table 1 provides descriptions of social media platforms that are used by these major CPA firms and, thus, encompassed in the current study.

\section{TABLE 1 \\ DESCRIPTION OF SOCIAL MEDIA PLATFORMS}

\begin{tabular}{|c|c|}
\hline Social Media & Description \\
\hline $\begin{array}{l}\text { Company } \\
\text { blog }\end{array}$ & $\begin{array}{l}\text { A company blog is a discussion or informational site. Blogs are a form of social } \\
\text { networking because they are often interactive, enabling visitors to leave comments. }\end{array}$ \\
\hline Facebook & $\begin{array}{l}\text { Facebook users create a personal profile, add other users as friends, and exchange } \\
\text { messages. Users may join common-interest user groups. }\end{array}$ \\
\hline Google + & $\begin{array}{l}\text { Google+ is Google's version of Facebook. Google+ Hangouts, a feature, provides a one } \\
\text { stop shop for communications, combining instant messaging, Internet phone calls, text } \\
\text { messaging, video messaging and group chats. }\end{array}$ \\
\hline Instagram & $\begin{array}{l}\text { Instagram is a photo-sharing and social networking service, which enables users to take } \\
\text { pictures and share them. }\end{array}$ \\
\hline Link & LinkedIn is a social network especially for people in professional jobs. \\
\hline Twitter & $\begin{array}{l}\text { With Twitter, users can send and read text-based messages containing up to } 140 \\
\text { characters. }\end{array}$ \\
\hline YouTube & $\begin{array}{l}\text { YouTube is a video-sharing social networking website in which users can upload and } \\
\text { watch videos. }\end{array}$ \\
\hline
\end{tabular}

Source: Adapted from Smith \& Smith (2018).

The first research question concerns which social media platforms are used by Australian CPA firms. On average, Australian CPA firms use 2.6 social media platforms. The most used platforms are LinkedIn, Facebook, and Twitter. In addition to these three, other social media sites used include YouTube, Google+, Instagram, and Blog. The percentage of firms using each social media platform is shown in Table 2.

What is surprising about these results is not which platforms are most popular, but the implication that Australian CPA firms might benefit by increasing their usage of social media as a marketing tool. LinkedIn is used by 93 percent of major US CPA firms (Smith \& Smith, 2018), whereas, it is used by only 78 percent of Australian CPA firms. Facebook and Twitter are used by 90 percent of US CPA firms (Smith \& Smith, 2018). These platforms are used less frequently by Australian CPA firms; 68 percent and 54 percent respectively. Each social media platform is less utilized in Australia, compared to usage in the US. As noted 
previously, social media can be used to increase positive brand awareness, which can lead to greater revenues. This study reveals that Australian CPA firms have an opportunity to increase their usage of social media as a means to connect with current and prospective clients.

TABLE 2

\section{SOCIAL MEDIA PLATFORMS MOST USED BY AUSTRALIAN CPA FIRMS}

\begin{tabular}{lr}
\hline Social Media Platform & \% Using \\
\hline LinkedIn & \\
Facebook & 78.4 \\
Twitter & 68.0 \\
YouTube & 54.6 \\
Google + & 25.8 \\
Instagram & 17.5 \\
Blog & 10.3 \\
\hline
\end{tabular}

With only a fourth of Australian CPA firms using YouTube, this marketing tool is especially underutilized. Many people use YouTube as a search engine to find information about a variety of topics. Watching a video instead of reading a document is often a preferred way to learn (Smith, Blazovich, \& Smith, 2015). YouTube allows a firm to tell a story, about its purpose, employees, services, and culture. Marketing a firm via YouTube videos can highlight the strong points of a firm in a powerful way that words and pictures alone cannot (Honigman, 2016).

The second research question concerns whether social media use varies according to total revenue, total partners, total offices, and the percentage of female partners. Table 3 lists each firm along with the factors used in the analysis, in the most recent period in which data was accessible. Firms are ranked by the number of social media platforms they use. Usage ranges from the most being six social media platforms to the least being none.

TABLE 3

MAJOR AUSTRALIAN CPA FIRMS: SOCIAL MEDIA PLATFORMS, REVENUE, PARTNERS, \% FEMALE PARTNERS, AND OFFICES

\begin{tabular}{|c|c|c|c|c|c|c|}
\hline & Australia CPA Firm & $\begin{array}{r}\text { Total } \\
\text { Social } \\
\text { Media } \\
\end{array}$ & $\begin{array}{c}\text { Revenue } \\
\text { 2016-17 } \\
\text { (A\$ Mill.) } \\
\end{array}$ & $\begin{array}{c}\# \\
\text { Part- } \\
\text { ners } \\
\end{array}$ & $\begin{array}{c}\% \\
\text { Female } \\
\text { Part- } \\
\text { ners } \\
\end{array}$ & $\begin{array}{c}\# \\
\text { Austra- } \\
\text { lian } \\
\text { Offices } \\
\end{array}$ \\
\hline 1 & BusinessDEPOT & 6 & 4.8 & 8 & 13.0 & 2 \\
\hline 2 & EY & 6 & 1630.0 & 540 & 24.0 & 7 \\
\hline 3 & $\mathrm{BDO}$ & 5 & 246.7 & 157 & 15.0 & 10 \\
\hline 4 & Deloitte & 5 & 1760.0 & 718 & 27.0 & 12 \\
\hline 5 & Fordham Group & 5 & 24.9 & 18 & 22.0 & 4 \\
\hline 6 & Kelly+Partners & 5 & 30.2 & 41 & 24.0 & 12 \\
\hline 7 & Kidmans Partners & 5 & 7.5 & 8 & 25.0 & 1 \\
\hline 8 & KPMG & 5 & 1500.0 & 516 & 24.0 & 14 \\
\hline 9 & MGR Accountants & 5 & 6.0 & 6 & 0.0 & 4 \\
\hline
\end{tabular}




\begin{tabular}{|c|c|c|c|c|c|c|}
\hline 10 & Pitcher Partners & 5 & 235.1 & 110 & 13.0 & 6 \\
\hline 11 & RSM & 5 & 181.4 & 94 & 9.0 & 30 \\
\hline 12 & William Buck & 5 & 104.5 & 77 & 14.0 & 5 \\
\hline 13 & WMS Chartered Accountants & 5 & 9.4 & 7 & 0.0 & 1 \\
\hline 14 & AGS Accounting & 4 & 3.4 & 5 & 20.0 & 4 \\
\hline 15 & Altus Financial & 4 & 11.5 & 9 & 11.0 & 2 \\
\hline 16 & Bentleys & 4 & 91.0 & 82 & 17.0 & 19 \\
\hline 17 & Change Accountants \& Advisors & 4 & 3.0 & 1 & 0.0 & 1 \\
\hline 18 & Grant Thornton & 4 & 229.2 & 149 & 17.0 & 6 \\
\hline 19 & hmh ADVISORY & 4 & 8.2 & 8 & 0.0 & 1 \\
\hline 20 & Hoffman Kelly Chartered Accountants & 4 & 6.4 & 4 & 25.0 & 1 \\
\hline 21 & Hood Sweeney & 4 & 19.0 & 12 & 17.0 & 2 \\
\hline 22 & Kearney Group & 4 & 7.1 & 7 & 29.0 & 1 \\
\hline 23 & LDB Accountants \& Advisors & 4 & 8.7 & 6 & 0.0 & 1 \\
\hline 24 & Mazars & 4 & 21.7 & 13 & 23.0 & 3 \\
\hline 25 & MWL Financial Group & 4 & 12.8 & 13 & 33.0 & 3 \\
\hline 26 & PKF & 4 & 107.9 & 91 & 14.0 & 13 \\
\hline 27 & Power Tynan & 4 & 6.7 & 6 & 50.0 & 3 \\
\hline 28 & Prosperity Advisers Group & 4 & 21.3 & 20 & 35.0 & 3 \\
\hline 29 & PwC & 4 & 2120.0 & 620 & 24.0 & 9 \\
\hline 30 & SRJ Walker Wayland & 4 & 6.7 & 5 & 20.0 & 3 \\
\hline 31 & Wilson Pateras & 4 & 7.2 & 6 & 0.0 & 2 \\
\hline 32 & WSC Group & 4 & 4.9 & 4 & 50.0 & 6 \\
\hline 33 & BM\&Y Accountants & 3 & 5.6 & 5 & 20.0 & 2 \\
\hline 34 & BMO Accountants & 3 & 5.8 & 4 & 25.0 & 1 \\
\hline 35 & Bonsella Business Solutions & 3 & 3.1 & 5 & 0.0 & 1 \\
\hline 36 & Collins \& Co & 3 & 6.5 & 4 & 0.0 & 1 \\
\hline 37 & Collins SBA & 3 & 5.2 & 8 & 13.0 & 1 \\
\hline 38 & Cutcher \& Neale & 3 & 18.9 & 9 & 0.0 & 2 \\
\hline 39 & dnm group & 3 & 1.2 & 2 & 0.0 & 1 \\
\hline 40 & dVT Group & 3 & 6.4 & 6 & 17.0 & 2 \\
\hline 41 & ESV Accounting and Business Advisors & 3 & 12.7 & 9 & 11.0 & 1 \\
\hline 42 & Fortunity & 3 & 6.1 & 6 & 17.0 & 1 \\
\hline 43 & Hill Rogers & 3 & 9.1 & 10 & 20.0 & 1 \\
\hline 44 & HLB Mann Judd & 3 & 96.5 & 80 & 13.0 & 10 \\
\hline 45 & KordaMentha & 3 & 120.0 & 44 & 11.0 & 6 \\
\hline 46 & Kothes Accounting Group & 3 & 5.5 & 7 & 14.0 & 0 \\
\hline 47 & MacKay Goodwin & 3 & 3.8 & 4 & 0.0 & 2 \\
\hline 48 & Moore Stephens & 3 & 50.1 & 57 & 7.0 & 7 \\
\hline 49 & Poole Group & 3 & 8.6 & 7 & 0.0 & 1 \\
\hline 50 & R J Sanderson \& Associates & 3 & 11.6 & 9 & 33.0 & 10 \\
\hline
\end{tabular}




\begin{tabular}{|c|c|c|c|c|c|c|}
\hline 51 & Roberts \& Morrow & 3 & 11.3 & 15 & 27.0 & 4 \\
\hline 52 & Rosenfeld Kant \& Co & 3 & 4.4 & 3 & 0.0 & 1 \\
\hline 53 & Rothsay Chartered Accountants & 3 & 6.6 & 7 & 0.0 & 1 \\
\hline 54 & SiDCOR Chartered Accountants & 3 & 13.0 & 2 & 0.0 & 4 \\
\hline 55 & Acute Business Services & 2 & 1.9 & 1 & 0.0 & 1 \\
\hline 56 & Australian Audit & 2 & 1.4 & 3 & 0.0 & 1 \\
\hline 57 & Banks Group & 2 & 18.3 & 16 & 6.0 & 3 \\
\hline 58 & Bell Partners (QId) & 2 & 1.5 & 2 & 0.0 & 5 \\
\hline 59 & Brentnalls & 2 & 28.8 & 27 & 19.0 & 6 \\
\hline 60 & Commercial Associates & 2 & 6.5 & 5 & 0.0 & 3 \\
\hline 61 & DLA Partners & 2 & 5.8 & 4 & 25.0 & 2 \\
\hline 62 & Ecovis Clark Jacobs & 2 & 6.9 & 5 & 20.0 & 1 \\
\hline 63 & Forsyths & 2 & 12.8 & 12 & 17.0 & 5 \\
\hline 64 & Hall Chadwick & 2 & 62.0 & 37 & 8.0 & 8 \\
\hline 65 & Marsh Tincknell Accountants & 2 & 10.1 & 11 & 9.0 & 5 \\
\hline 66 & MOR Accountants & 2 & 11.5 & 9 & 0.0 & 2 \\
\hline 67 & Murray Nankivell & 2 & 7.4 & 7 & 0.0 & 3 \\
\hline 68 & Rede Accountants & 2 & 3.6 & 2 & 0.0 & 1 \\
\hline 69 & StewartBrown & 2 & 11.5 & 7 & 29.0 & 2 \\
\hline 70 & Synergy Group & 2 & 30.0 & 9 & 22.0 & 1 \\
\hline 71 & TGS Partners & 2 & 3.4 & 2 & 0.0 & 1 \\
\hline 72 & Allan Hall Business Advisors & 1 & 15.4 & 9 & 11.0 & 2 \\
\hline 73 & Bedford CA & 1 & 14.1 & 10 & 10.0 & 1 \\
\hline 74 & Bush \& Campbell & 1 & 7.0 & 8 & 50.0 & 3 \\
\hline 75 & CountPlus & 1 & 87.6 & 59 & 15.0 & 28 \\
\hline 76 & Economos & 1 & 9.9 & 6 & 3.0 & 1 \\
\hline 77 & Evolv & 1 & 3.0 & 3 & 33.0 & 1 \\
\hline 78 & LBW Business and Wealth Advisors & 1 & 7.5 & 6 & 0.0 & 2 \\
\hline 79 & LMS Advisory & 1 & 2.3 & 3 & 0.0 & 1 \\
\hline 80 & Pooles Accountants \& Tax Specialists & 1 & 5.0 & 4 & 0.0 & 5 \\
\hline 81 & Rhodes Docherty \& Co & 1 & 4.0 & 4 & 50.0 & 1 \\
\hline 82 & UHY Haines Norton & 1 & 36.1 & 36 & 17.0 & 9 \\
\hline 83 & Walker Wayland Australasia & 1 & 70.4 & 64 & 20.0 & 28 \\
\hline 84 & 2020 Global Business Consultants & 0 & 1.5 & 2 & 0.0 & 1 \\
\hline 85 & Anderson Munro \& Wyllie & 0 & 1.7 & 2 & 0.0 & 1 \\
\hline 86 & AZ Next Generation Advisory & 0 & 37.7 & 29 & 14.0 & 18 \\
\hline 87 & BDJ Partners & 0 & 5.4 & 5 & 0.0 & 1 \\
\hline 88 & Blaze Acumen & 0 & 11.0 & 8 & 25.0 & 1 \\
\hline 89 & Cor Cordis Chartered Accountants & 0 & 26.3 & 18 & 6.0 & 4 \\
\hline 90 & DBW Group & 0 & 3.4 & 2 & 0.0 & 1 \\
\hline 91 & DFK Australia New Zealand & 0 & 58.9 & 50 & 12.0 & 19 \\
\hline
\end{tabular}




\begin{tabular}{|c|c|c|c|c|c|c|}
\hline 92 & Doyle Partners & 0 & 4.6 & 4 & 0.0 & 1 \\
\hline 93 & Findex & 0 & 371.5 & 234 & 22.0 & 81 \\
\hline 94 & Lowe Lippmann Chartered Accountants & 0 & 16.0 & 7 & 0.0 & 1 \\
\hline 95 & LWM Group & 0 & 4.6 & 3 & 0.0 & 1 \\
\hline 96 & Pluta Accountants & 0 & 1.4 & 2 & 50.0 & 1 \\
\hline \multirow[t]{4}{*}{97} & The Bennett Group & 0 & 1.8 & 2 & 0.0 & 1 \\
\hline & Average & 2.6 & 101.9 & 45.4 & 13.6 & 5.3 \\
\hline & Top 32 Average ( $>3$ platforms) & 4.5 & 263.7 & 105.0 & 18.6 & 6.0 \\
\hline & Bottom 26 Average ( $<2$ platforms) & 0.5 & 31.1 & 22.3 & 13.0 & 8.2 \\
\hline
\end{tabular}

Note: A total of 97 firms were included in the analysis. Total revenue figures are for fiscal year 2016-2017. For three firms in the top 100, social media data (via websites) were unavailable: Nexia Australia (ranked 14th), Powers Financial Group (46th, merged with Moore Stephens), and Elliott House (82nd).

Shown in Table 4 are results of the t-tests regarding social media platforms, firm revenue, total partners, number of offices, and percent of female partners. The average number of platforms for the top 32 firms ( 4 or more platforms) was compared to the bottom 26 firms ( 1 or fewer platforms). The top 32 firms averaged 4.5 social media platforms; the bottom 26 average 0.5 platforms, which was significantly different $(\mathrm{p}<.000)$. The average revenue for the top 32 (4 or more platforms) was A\$263.7 million versus A\$ 31.1 million for the bottom 26 ( 1 or fewer platforms), which was significantly different $(\mathrm{p}<.016)$.

\section{TABLE 4 \\ RESULTS OF T-TESTS OF AUSTRALIAN CPA FIRMS RANKED BY SOCIAL MEDIA USE: REVENUE, PARTNERS, OFFICES, AND PERCENT FEMALE PARTNERS}

\begin{tabular}{lccccc}
\hline $\begin{array}{l}\text { Ranked by } \\
\text { \# Social } \\
\text { Media } \\
\text { Platforms }\end{array}$ & $\begin{array}{c}\text { Average \# } \\
\text { Social } \\
\text { Media } \\
\text { Platforms* }\end{array}$ & $\begin{array}{c}\text { Average } \\
\text { Revenue } \\
\text { (A\$ } \\
\text { Mill.)** }\end{array}$ & $\begin{array}{c}\text { Average \# } \\
\text { of } \\
\text { Partners }^{\circledR}\end{array}$ & $\begin{array}{c}\text { Average \# } \\
\text { of } \\
\text { Offices }\end{array}$ & $\begin{array}{c}\text { Average } \\
\text { Percent of } \\
\text { Female } \\
\text { Partners }\end{array}$ \\
Top 32 Firms & 4.5 & 263.7 & 105.0 & 6.0 & 18.6 \\
Bottom 26 Firms & 0.5 & 31.1 & 22.3 & 8.2 & 13.0 \\
All Firms & 2.6 & 101.9 & 45.4 & 5.3 & 13.6 \\
\hline
\end{tabular}

\footnotetext{
*T-Test Results, Significant Difference, $\mathrm{p}<.000$.

**T-Test Results, Significant Difference, $\mathrm{p}<.016$.

@ T-Test Results, Significant Difference, $\mathrm{p}<.013$.

@@T-Test Results, No Significant Difference, $\mathrm{p}<.262$.

\&T-Test Results, Significant Difference, $\mathrm{p}<.082$.
}

The firms had on average 45.4 partners. Comparing firms with the most social media platforms to firms with the fewest platforms, those with the most platforms had an average of 105.0 partners and those with the fewest platforms had an average of 22.3 partners. This was a significant difference $(\mathrm{p}<.013)$. Regarding number of offices, firms had an average of 5.3 offices per firm. The firms using the most social media platforms averaged 6.0 offices per firm versus 8.2 offices per firm for the firms with the fewest platforms. This difference was not significant $(\mathrm{p}<.262)$. Thus, the number of offices in a firm had no relationship to the number of social media platforms used. 
For over 15 years, women have comprised the majority of Australian accounting graduates; however, women have been underrepresented in senior roles (Adapa, Rindfleish, \& Sheridan, 2016). As a result, a small overall percentage of female partners would be expected. As shown in Table 4, only 13.6 percent of partners are females. The firms that make the most use of social media platforms average 18.6 percent female partners per firm versus 13.0 percent for firms that make the least use of social media platforms. The difference was significant $(\mathrm{p}<.082)$. Thus, firms that use more social media platforms tend to have a higher proportion of female partners. A gender difference exists in the firm partnership relative to social media use.

\section{CONCLUSIONS}

This study examined social media use according to firm size, as measured by total revenue, total partners, and total offices. In addition, we examined whether social media use varies by top management characteristics, specifically gender make-up, as measured by the percentage of female partners.

The first research question concerned which social media platforms are being used by major Australian CPA firms. Results show that the most widely used social media platforms are LinkedIn, Facebook, and Twitter, with 78.4 percent, 68.0 percent, and 54.6 percent of firms, respectively. On average, Australian CPA firms use 2.6 social media platforms. These percentages take on a new meaning when compared to counterparts, such as US accounting firms. Ninety percent or more of US accounting firms use LinkedIn, Facebook, and Twitter. Since research shows that social media can be used to increase brand awareness and connect with clients, Australian CPA firms have a marketing tool at their disposal that is not being used to its full potential.

The second research question concerned whether social media use varies according to the firm's total revenue, total partners, total offices, and the percentage of female partners. Firms were ranked according to social media platform use; firms that use more social media platforms were compared to those using less. Firms using more platforms had significantly higher revenue. This suggests that firms with higher revenues could perceive that social media is necessary for engaging clients and keeping the firm name visible in the marketplace. Of course, with greater revenue, firms can afford to pay for higher social media visibility. Firms with more partners on average used more social media. The number of partners can be correlated to the size of the firm. Another suggestion is that the increase in partners represents a greater diversity of social media use by partners and, thus, a higher perception of the value of different platforms connecting to clients and other constituents

Interestingly, there was no significant difference in the average number of offices between firms using more social media platforms and firms using less. The number of offices may be less a factor of firm size due to the typical locations of CPA firms in Australia. Large firms tend to have offices in major business centres, whereas, smaller CPA firms have offices in both the major and smaller business centres.

The proportion of female partners at a firm was significantly higher for firms using more social media platforms as compared to firms using fewer platforms. This gender difference connected to CPA firms and social media use might suggest a gender difference in appreciation of the value of social media.

\section{LIMITATIONS AND FUTURE RESEARCH}

The study is limited in several ways, including the time period used, the firms included in the sample, and the methodology. Future studies could use this study as a starting benchmark for future longitudinal analysis of Australian CPA firms and trends in social media use. Future studies could include other CPA firms, such as those not among the top 100. Other methodologies could be employed, including other demographic factors. Social media use is expected to increase, thus making it a viable topic for future studies.

Future research may examine individual purposes for using social media, such as disseminating information, marketing the firm's services, and managing stakeholder relationships. Supporting these purposes with consumer behavior theories can further enhance social media research among CPA firms. 
Also, in future studies, different measures of social media usage could be investigated, such as number of followers, frequency of posting, etc. This would provide measures of "intensity" of social media use.

\section{DATA AVAILABILITY}

The data that support the findings of this study are available from the corresponding author upon reasonable request.

\section{REFERENCES}

Adapa, S., Rindfleish, J., \& Sheridan, A. (2016). 'Doing gender' in a regional context: Explaining women's absence from senior roles in regional accounting firms in Australia. Critical Perspectives on Accounting, 35, 100-110.

AFR. (2018). Financial Review Top 100 Accounting Firms. Australian Financial Review. Retrieved September 28, 2018, from https://caanz-top-100.afr.com/top-100-accounting-firms/

Alarcón-del-Amo, M.C., Rialp-Criado, A., \& Rialp-Criado, J. (2018). Examining the impact of managerial involvement with social media on exporting firm performance. International Business Review, 27(2), 355-366.

Aral, S., \& Walker, D. (2011). Creating Social Contagion Through Viral Product Design: A Randomized Trial of Peer Influence in Networks. Management Science, 57(9), 1623-1639.

Baird, C.H., \& Parasnis, G. (2011). From social media to social customer relationship management. Strategy \& Leadership, 39(5), 30-37.

Baird, S.M., Marsh, P.A., Lawrentschuk, N., Smart, P., \& Chow, Z. (2019). Analysis of social media use among Australian and New Zealand otolaryngologists. ANZ Journal of Surgery, 89(6), 733-737.

Barnes, N.G. (2010). Tweeting and blogging to the top. Marketing Research, 22(1), 8-13.

Berthon, P.R., Pitt, L.F., Plangger, K., \& Shapiro, D. (2012). Marketing meets Web 2.0, social media, and creative consumers: Implications for international marketing strategy. Business Horizons, 55(3), 261-271.

Brink, T. (2017). B2B SME management of antecedents to the application of social media. Industrial Marketing Management, 64, 57-65.

Carr, C.T., \& Hayes, R.A. (2015). Social media: Defining, developing, and divining. Atlantic Journal of Communication, 23(1), 46-65.

Chamberlain, D., Rudolph, H., \& Smith, L.M. (2019b, January 7). Analysis of social media usage and relationship to firm size and revenue growth among major CPA firms. Services Marketing Quarterly, 40(1), forthcoming. https://doi.org/10.1080/15332969.2018.1514798

Chamberlain, D., Rudolph, H., Smith, K.T., \& Smith, L.M. (2019a). Analysis of social media usage and relationship to revenue among major energy companies. Oil, Gas \& Energy Quarterly, 67(3), 525-538.

Culnan, M.J., McHugh, P.J., \& Zubillaga, J.I. (2010). How large US companies can use Twitter and other social media to gain business value. MIS Quarterly Executive, 9(4), 243-259.

DePietro, R., Wiarda, E., \& Fleischer, M. (1990). The context for change: Organization, technology and environment. In L.G. Ornatzky \& M. Fleischer (Eds.), The processes of technological innovation (pp. 151-175). Lexington, MA: Lexington Books.

DeSanctis, G., \& Poole, M.S. (1994). Capturing the complexity in advanced technology use: Adaptive structuration theory. Organization Science, 5(2), 121-147.

Dooley, J.A., Jones, S.C., \& Iverson, D. (2014). Using Web 2.0 for Health Promotion and Social Marketing Efforts: Lessons Learned From Web 2.0 Experts. Health Marketing Quarterly, 31(2), 178-196.

Dwivedi, Y.K., Kelly, G., Janssen, M., Rana, N.P., Slade, E.L., \& Clement, M. (2018). Social Media: The Good, the Bad, and the Ugly. Information Systems Frontiers, 20(3), 419-423. 
Eschenbrenner, B., Nah, F.F.H., \& Telaprolu, V.R. (2015). Efficacy of Social Media Utilization by Public Accounting Firms: Findings and Directions for Future Research. Journal of Information Systems, 29(2), 5-21.

Etter, M., Ravasi, D., \& Colleoni, E. (2019). Social Media and the Formation of Organizational Reputation. Academy of Management Review, 44(1), 28-52.

Forbes, S.L., Goodman, S., \& Dolan, R. (2015). Adoption of social media in the Australian and New Zealand wine industries. Journal of New Business Ideas \& Trends, 13(2), 1-14.

Franco, M., Haase, H., \& Pereira, A. (2016). Empirical study about the role of social networks in SME performance. Journal of Systems and Information Technology, 18(4), 383-403.

Guinan, P.J., Parise, S., \& Rollag, K. (2014). Jumpstarting the use of social technologies in your organization. Business Horizons, 57(3), 337-347.

Hanna, R., Rohma, A., \& Crittendenb, V.L. (2011). We're all connected: The power of the social media ecosystem. Business Horizons, 54(3), 265-273.

Hao, J., Shi, H., Shi, V., \& Yang, C. (2020). Adoption of automatic warehousing systems in logistics firms: A technology-organization-environment framework. Sustainability, 12(12), 5185.

Hoffman, D.L., \& Fodor, M. (2010). Can you measure the ROI of your social media marketing? MIT Sloan Management Review, 52(1), 41-49.

Honigman, B. (2016). 24 Outstanding statistics \& figures on how social media has impacted the health care industry. Referral md. Retrieved September 30, 2019, from https://getreferralmd.com

Huang, J., Baptista, J., \& Galliers, R.D. (2013). Reconceptualizing rhetorical practices in organizations: The impact of social media on internal communications. Information \& Management, 50(2-3), $112-124$.

Kaplan, A.M., \& Haenlein, M. (2010). Users of the world, unite! The challenges and opportunities of Social Media. Business Horizons, 53(1), 59-68.

Kapoor, K.K., Tamilmani, K., Rana, N.P., Patil, P., Dwivedi, Y.K., \& Nerur, S. (2018). Advances in Social Media Research: Past, Present and Future. Information Systems Frontiers, 20(3), 531-558.

Karahanna, E., Xu, S.X., Xu, Y., \& Zhang, N. (2018). The needs-affordances-features perspective for the use of social media. MIS Quarterly: Management Information Systems, 42(3), 737-756.

Kietzmann, J.H., Hermkens, K., McCarthy, I.P., \& Silvestre, B.S. (2011). Social media? Get serious! Understanding the functional building blocks of social media. Business Horizons, 54(3), 241251.

Laverie, D.A., Humphrey, W.F., Velikova, N., Dodd, T.H., \& Wilcox, J.B. (2011). Building wine brand communities with the use of social media: A conceptual model. In Proceedings of the 6th AWBR International Conference, 9-10 June. France: Bordeaux Management School.

Lin, H.F. (2014). Understanding the determinants of electronic supply chain management system adoption: Using the technology-organization-environment framework. Technological Forecasting and Social Change, 86, 80-92.

Linnhoff, S., Volovich, E., Martin, H.M., \& Smith, L.M. (2017). An Examination of Millennials' Attitudes Toward Genetically Modified Organism (GMO) Foods: Is it Franken-Food or SuperFood? International Journal of Agricultural Resources, Governance and Ecology, 13(4), 371390.

Liu, W., Sidhu, A., Beacom, A.M., \& Valente, T.W. (2017). Social network theory. The International Encyclopedia of Media Effects, pp. 1-12. Hoboken, New Jersey: John Wiley \& Sons, Inc.

Mangold, W.G., \& Smith, K.T. (2011). Selling to Millennials with online reviews. Business Horizons, 55(2), 141-153.

Martin, H.M., Durr, D, Smith, L.M., Finke, R., \& Cherry, A. (2017). Analysis of GMO food products companies: Financial risks and opportunities in the agriculture industry. African Journal of Economic and Sustainable Development, 6(1), 1-17.

Martin, H.M., Smith, K.T., \& Smith, L.M. (2016). A financial and public policy analysis of the meat industry. International Journal of Economics and Accounting, 7(1), 74-88.

184 Journal of Accounting and Finance Vol. 21(5) 2021 
Martin, H.M., Smith, K.T., \& Smith, L.M. (2017). Using Social Audits to Detect and Eliminate Human Trafficking in Corporate Supply Chains. Internal Auditing, 32(1), 31-38.

Momany, M., \& Alshboul, A. (2016). Social media marketing: Utilizing social media to advance brand awareness and increase online sales. International Journal of Business, Marketing, \& Decision Science, 9(1), 33-54.

Monesson, E.P. (2014). Position yourself as a though leader on social media. CPA Practice Management Forum, 10(2), 7-9.

Moses, R.E., McNeese, L.G., Feld, L.D., \& Feld, A.D. (2014). Social Media in the Health-Care Setting: Benefits but Also a Minefield of Compliance and Other Legal Issues. American Journal of Gastroenterology, 109(8), 1128-1132.

O'Reilly, T. (2007). What Is Web 2.0: Design Patterns and Business Models for the Next Generation of Software. University Library of Munich, Germany, MPRA Paper, 65.

Olanrewaju, A.S.T., Hossain, M.A., Whiteside, N., \& Mercieca, P. (2020). Social media and entrepreneurship research: A literature review. International Journal of Information Management, 50, 90-110.

Petronio, S. (1991). Communication boundary management: A theoretical model of managing disclosure of private information between marital couples. Communication Theory, 1(4), 311-335.

Rudman, R.J. (2007, September). Web 2.0 The Internet is versioning... 1.0, 2.0. Accountancy SA, pp. 24 27.

Sawhney, R. (2009). Broken Guitar Has United Playing the Blues to the Tune of \$180 Million. Retrieved September 25, 2019, from https://www.fastcompany.com/1320152/broken-guitar-has-unitedplaying-blues-tune-180-million

Seraj, M. (2012). We Create, We Connect, We Respect, Therefore We Are: Intellectual, Social, and Cultural Value in Online Communities. Journal of Interactive Marketing, 26(4), 209-222.

Shirky, C. (2010). Cognitive surplus: How technology makes consumers into collaborators. New York: Penguin.

Smith, K.T. (2017). Hospital marketing and communications via social media. Services Marketing Quarterly, 38(3), 187-201.

Smith, K.T., \& Smith, L. M. (2018). Social Media Usage by CPA Firms According to Firm Services and Size. Journal of Accounting and Finance, 18(10), 112-126.

Smith, K.T., Blazovich, J., \& Smith, L.M. (2015). Social media adoption by corporations: An examination by platform, industry, size, and financial performance. Academy of Marketing Studies Journal, $19(2), 127-143$.

Stelzner, M. (2011). Social media marketing industry report. Retrieved September 25, from http://www.socialmediaexaminer.com/social-media-marketing-industry-report-2011/

Swati, P. (2021). Australia's economy booms to pre-pandemic levels as consumers, businesses spend. Reuters. Retrieved June 25, 2021, from https://www.reuters.com/world/asia-pacific/australia-gdpclimbs-18-q1-back-pre-pandemic-time-2021-06-02/

Tajvidi, R., \& Karami, A. (2017). The effect of social media on firm performance. Computers in Human Behavior. In Press. Retrieved from https://www.sciencedirect.com/science/article/pii/S0747563217305514

Toombs, L.A., \& Harlow, R.M. (2014). More than just "like": An entrepreneurial approach to creating a social media ethos in small firms. Academy of Marketing Studies Journal, 18(2), 275-286.

Uyar, A., \& Boyar, E. (2015). An Investigation into Social Media Usage of Publicly Traded Companies. Journal of Corporate Accounting \& Finance, 27(1), 71-78.

Weinberg, B.D., \& Pehlivan, E. (2011). Social spending: Managing the social media mix. Business Horizons, 54(3), 275-282.

Williams, B. (2017). There are now over 3 billion social media users in the world. Retrieved September 30, from https://mashable.com/2017/08/07/3-billion-global-social-media-users/

Yang, J.H., \& Liu, S. (2017). Accounting narratives and impression management on social media. Accounting and Business Research, 47(6), 673-694. 
Yuan, L. (2018). Young people in China don't know the internet we do-and they like it that way. Retrieved September 20, from https://www.independent.co.uk/life-style/gadgets-andtech/features/china-internet-social-media-great-firewall-of-china-censorship-apps-a8510036.html

Zeng, D., Chen, H., Lusch, R., \& Li, S-H. (2010). Social Media Analytics and Intelligence. IEEE Intelligent Systems, 25(6), 13-16. 